\title{
Market Response to the Addition and Deletion of Participation Index: Evidence from Turkey
}

\author{
Selim Baha YILDIZ1 ${ }^{1}$ Khaldoun Dia-Eddine ${ }^{2}$
}

\begin{abstract}
This paper investigates the impact of index additions (deletions) on the stock price and trading volume of the Participation-30 Index in Turkey, over the period April 2011 - June 2015, by using event study methodology. Results show that stock prices generally respond negatively to index additions and positively to index deletions during the research periods. Trading volumes of added and deleted stocks are affected positively in the announcement day; while the effective day exhibits the exact opposite behaviour. According to our findings, results of Participation-30 Index in Turkey are similar to the non-Muslim countries' results found in the previous studies.
\end{abstract}

Key Words: Participation Index; Event Study; Index Addition; Index Deletion

\section{Introduction}

The conventional finance has not been stabilized from 2008 global economic crisis to the present. Besides, Islamic Finance appears to be more stable than the conventional finance especially during crisis period when Islamic Finance has continued without interruption in growth (Arouri, Ben Ameur, Jawadi, Jawadi, \& Louhichi, 2013). In 2014, global Islamic Finance markets stand at USD 1.814 tr, representing a 9.4\% rise from USD $1.66 \mathrm{tr}$ in 2013. As the end of the 2020, the total assets of Islamic Finance sector is expected to increase by $10 \%$ per annum and reach USD 3.24 tr. The major players remain Gulf Cooperation Council (GCC) countries and Malaysia. Meanwhile non-tradional markets for Islamic Finance are becoming evident with African and East Asia countries; and the interest of Western countries will continue to increase steadily (State of the Global Islamic Economy Report 2015-2016 Report, 2015).

Islamic Capital Market which is one of the three main branches of Islamic Finance has improved significantly at end of the 90's with regards to complexity and size. One of

1 Assistant Professor, Faculty of Business Administration, Celal Bayar University, Turkey, E-mail: baha.yildiz@cbu.edu.tr, Tel: +90236231 3913

2 Head of Center for Middle East \& Africa Business, School of Management and Law, Zurich University of Applied Sciences, Switzerland, E-Mail: diak@zhaw.ch, Tel: +410589346615 
the aspects of this improvement is the launch of Shariah compliant indices, which is a part of faith-based or morally responsible investments (Ghoul \& Karam, 2007). The first Islamic indices DMI 150 (Dar al Mal al-Islami) and SAMI (Socially Aware Muslim Index) were released in 1998. One year later primary index providers Dow Jones and Financial Time Stock Exchange Group created their own indices named Dow Jones Islamic Market Index (DJIMI) and Global Islamic Index Series (GIIS) respectively. In the next years the other global integrated index providers such as Standard and Poor's, Morgan Stanley Capital International, and Stoxx Group activated their own Islamic Indices (El Khamlichi, Sannajust,\& Sarkar, 2014). Islamic stock market indices have gained popularity due to the greater potential of growth and profitability (Hassan,\& Girard, 2011) and (Ho, Abd Rahman, Yusuf, \& Zamzamin, 2014).

In Turkey, the interest for Islamic investments together with the appropriateness of the political environment has grown in the last decades. As a natural consequence of the growth, Islamic financial product range and number has increased and Participation Index ${ }^{3}$, which is in compliance with the principles of participating banking, started to be calculated as of 06.01.2011. Companies to be admitted to Participation-30 Index are determined in two phases; namely core activity and financial criteria as in other similar Islamic Indices. In the first phase, the Participation Indices exclude companies whose core activity is one of the following: interest-based financing, trade, services, intermediation (banking, insurance, financial leasing, factoring, and other interest-based activities), alcoholic beverages, gambling, games of chance, pork and similar food, press, publications and advertisement, tourism, entertainment, tobacco products, weapons, and futures gold, silver and currency trade. Companies passing the first screen are then checked using a second screen examining for compliance in financial ratios. These are;

1. Total interest loans / Market value $<30 \%$,

2. Interest bearing cash and securities / Market value $<30 \%$,

3. Income from non-permissible activities / Total Income $<5 \%$.

The determined stocks are listed in descending order in terms of market value of stocks in active circulation. Top 30 stocks make up the Index (Participation-30 Index Rules Booklet). In the case of equities, the differences between Shariah compliant stocks and

3 The index name "Participation Index" was changed to Participation-30 Index as of 09.07.2014 since the other indices (Participation 50 and Participation Model Portfolio) also started to be calculated. 
their conventional forms are even less significant, only requires screenings (Sadeghi, 2015).

At present, there are many Islamic Indices formed by different institutions. Among the Islamic Indices, filtering process is very similar to each other but there is no exact standardization according to the financial ratio filtering. This difference is due to the diversity in the perspectives to provisions of Shariah (Yanpar, 2014) and the scarcity of qualified Shariah scholars. Individual investors with Islamic sensitivity and Islamic fund managers can determine which stocks are eligible for investing, by looking at the contents of Islamic Index. Also addition/deletion to the Islamic Indices is a critical phenomenon from a religious viewpoint since Islamic funds should be adjusted to their portfolios according to the new situation. While an inclusion into the list may or may not attract new funds (depend on the universe of eligible stocks and the available substitutes to the stock), a deletion will require portfolio rebalancing by Islamic funds (Abdullah, \& Bacha, 2001).

The purpose of this paper is to investigate the impacts of index additions (deletions) on the return and trading volume of the Participation-30 Index in Turkey, by using event study methodology. Furthermore, this study contributes to the limited literature of Participation Index of Turkey. The rest of the paper is organized as follows. Section 2 presents relevant literature. Section 3 describes the data set and explains the methodology we followed. Section 4 discusses the empirical results and Section 5 concludes the paper.

\section{Literature Review}

The issue of additions and deletions to stock indices has been widely studied in finance. The existing literature shows that additions of stocks to major stock indices usually results in higher trade volume and returns, deletions are known to reduce returns (Chakrabarti, Huang, Jayaraman,\& Lee, 2005). Yet there is not much comprehensive academic research related to the effect of the revision of Islamic Indices on the stocks returns and trading volumes. The literature for Participation Index in Turkey is also very limited. Studies on these two issues are summarized below.

Most of the studies related to how the revision of Islamic Indices affects the stocks returns and trading volumes are performed in Malaysia which is one of the pioneer countries of Islamic Finance. Abdullah and Bacha (2001) examined the impact of stocks that have either been added or deleted from the list of halal stocks (the list of approved companies by Malaysian Shariah Advisory Council) on the returns and 
trading volumes. Their findings suggest that additions in the list result in a positive impact while a negative impact occurs by deletions.

Sadeghi (2008) investigated the impact of the introduction of Shariah compliant Index (SI) by Bursa Malaysia on the performance and liquidity of included stocks, using an event study to estimate the mean cumulative abnormal returns in the days surrounding the event. The results show that, overall, the introduction of SI has a positive impact on the financial performance of included stocks and their liquidity over a longer period.

Malaysian Shariah Advisory Council revised the methodology in screening stocks for Shariah compliance on $29^{\text {th }}$ November 2013. Yazi, Morni and Saw (2015) examined the new situation and find that the inclusion of a stock in the Shariah compliant list has a positive effect on the value of the stock; while removal from the list negatively affects the price of the stock. Ameer (2015) estimated the idiosyncratic risk of Shariah compliant stocks included (excluded) from FTSE Bursa Malaysia Emas Index and according to their results, before stocks are included in the Shariah Index, these stocks tend to exhibit higher idiosyncratic risk, and after inclusion in the Shariah Index, these stocks tend to exhibit lower idiosyncratic risk.

Apart from Malaysia studies, Sadeghi (2014) has investigated the impacts of index addition and deletion using a sample of 117 companies added to and 87 companies deleted from the DJIM index over the period January 2006 - December 2009. His results suggest that stock prices respond negatively to index additions, and positively to index deletions. Furthermore, his study provides overwhelming evidence in support of long-term decline in the returns and liquidity of added stocks, and long-term improvement in the returns of the deleted stocks.

Sadeghi (2011) also investigated the impacts of index additions on the return and liquidity of Shariah compliant stocks in Kuwait, Oman, Qatar, and UAE. The findings show that stock prices respond positively to index addition events; whereas, the effect of the liquidity of added stocks changes depending on the country and the liquidity measures. Febrian, Erwany and Primadhi (2013) study the market response to composition change of Jakarta Islamic Index. Results show that the market reacts positively to stocks newly included in the Islamic Index leading to the improvement of their returns and vice versa.

The studies related to the Participation Index in Turkey are limited. Savaşan, Yardımoğlu and Beşel (2015) investigate the effects of exogenous shocks on Participation-30 Index. The results suggest that there is an exogenous shock and its impact on Participation-30 
Index will be permanent. Y1ldiz (2015) examines the risk and return characteristics of Participation-30 Index and BIST 100 Index during the period of January 2011 October 2014. According to the results, the Islamic filtering does not have an adverse effect on the Participation-30 Index performance.

\section{Data and Methodology}

The aim of this study is to evaluate the effects of additions or deletions from Participation-30 Index on the returns and trading volumes of stocks, from April 2011 to June 2015, for 18 revision periods. Participation Index has been calculated as the price and yield indices of simultaneous data beginning from 06 January 2011 to include top 30 eligible companies and reviewed and adjusted on a quarterly basis. The resulting changes to the index composition are announced before two days from the effective date $^{4}$. This study comprises 18 revision periods. In these revision periods, 75 stocks are added and 75 stocks are deleted from the Participation-30 Index. Thus the whole sample consists of 150 stocks but we use 51 stocks for addition and 30 stocks for deletion in the analysis. The reasons for the excluded stocks are; 7 of them do not have enough historical data within 120 days preceding the announcement date. Since 63 stocks has been added or deleted in one or two previous index period, they overlap with the estimation period of 120 days. These stocks are also excluded from the analysis to ensure the reliability of the estimation period. Lastly, 1 stock is removed for the reason that the board was closed for a while within the estimation period.

The data used in the present study are obtained from the website of İş Investment and Bizim Securities. Data series consisting of daily stock prices, trading volumes and daily index time series are collected from İş Investment Remaining data such as effective and announcement dates of the additions and deletions are gathered from Bizim Securities. All stock prices are adjusted for dividends, rights issues, and stock splits.

To estimate the impact of the additions to and deletions from the Participation-30 Index, we applied event study methodology. Our methodology broadly follows the approach in Lynch and Mendenhall (1996), Consolandi, Jaiswal-Dale, Poggiani and Vercelli

4 In the first years of Participation-30 Index, the resulting changes to the index composition are announced to range from 1 to 4 trading days before the effective date. In this study, due to the lack of data we use the first two trading days after the announcement date. Also when the revision in the index composition was declared after the trading session, announcement date was accepted to be the next trading day. 
216 Journal of Islamic Economics, Banking and Finance, Vol-12, No. 4, Oct - Dec, 2016

(2009) and Cheung and Roca (2013). We further divide the whole event window into five sub-windows in order to evaluate different aspects of stock behavior around the events. Sub-windows are displayed in Table 1.

Table 1:Sub-windows of the Whole Event Window

\begin{tabular}{|l|l|l|}
\hline Interval Name & Interval Time & Interval Explanation \\
\hline Pre-Announcement & AD-5,...AD-1 & $\begin{array}{l}\text { For the existence of any anticipation or leakage } \\
\text { of information }\end{array}$ \\
\hline Announcement & AD & Announcement date of the new index composition \\
\hline Post-Announcement & AD $+1, \mathrm{AD}+2$ & $\begin{array}{l}\text { Comprise from day after announcement date till } \\
\text { effective date }\end{array}$ \\
\hline Effective & ED & Actualizing day of index revision \\
\hline Post-Effective & ED $+1 \ldots \mathrm{ED}+5$ & The first 5 trading days after the index revision \\
\hline
\end{tabular}

Since an event study analyzes the abnormal performance, modeling the expected returns has a special importance (Basdas \& Oran, 2014). In order to obtain abnormal returns, the Market Model is preferred. Holler (2014) has found in his meta research that the market model is the predominant model for predicted expected returns (www. eventstudytools.com). The abnormal returns are estimated according to the market model as follows:

$$
A R_{i t}=R_{i t}-\alpha_{i}-\beta_{i}\left(R_{m t}\right)
$$

where $A R_{i t}$ is the abnormal return for stock $i$ at time $t, R_{i t}$ is the realized return for stock $i$ at time $t, R_{m t}$ is the market return on day $t$ (BIST 100 Index as proxy for market's return), $\alpha_{i}$ and $\beta_{i}$ are the coefficients calculated through an OLS regression model using logarithmic daily returns of stocks and market during analysis period. We estimate the expected return using data for a 120 day period before the event window (AD-125...AD-6).

To test for the significance of the abnormal return (or trading volumes) over the event period, MacKinlay (1997) supports the idea of using non-parametric tests together with parametric tests. Hence we apply both parametric and non-parametric tests. The parametric one is Boehmer, Musumeci and Poulsen (1991) (hereafter BMP) t-statistic adjusted for cross-sectional correlation proposed by Kolari and Pynnönen (2010); and the non-parametric one is Wilcoxon Signed Ranks test.

First of all, the abnormal returns on stock i on the event day E are standardized by the estimation period standard deviation $\left(S A R_{i, E}\right)$. The estimation period is from $\mathrm{AD}^{-125}$ to $\mathrm{AD}-6$. 


$$
S A R_{i, E}=\frac{A R_{i, E}}{\sigma_{i} \sqrt{1+\left(\frac{1}{T_{i}}\right)+\frac{\left(R_{m, E}-\bar{R}_{m, e}\right)^{2}}{\sum_{t=1}^{T}\left(R_{m, t}-\bar{R}_{m, e}\right)}}}
$$

where $S A R_{i, E}$ is the standardized abnormal return of stock $i$ on the event date $E ; A R_{i, E}$ represents stock $i$ 's abnormal return on the event day; $\sigma_{i}$ is the standard deviation of security $i$ during the estimation period; $T_{i}=120$ is the number of trading days used as the estimation period $e$ for the stock $i ; R_{m, E}$ is the market return on the event window/ date $E ; \bar{R}_{m, E}$ is the average market return on the estimation period $e ; R_{m, t}$ and is the market return on day $t$.

Then, BMP t-statistic is computed as follows:

$$
t_{B M P}=\frac{\left(\frac{1}{N}\right) \sum_{i=1}^{n} S A R_{i, E}}{\sqrt{\sigma_{S A R_{i, E}}^{2} / N}}
$$

where $N$ is the number of firms in the sample and $\sigma_{S A R_{i, E}}^{2}$ is the variance of $S A R_{i, E}$. Strength of using BMP t-statistic is that it accounts for event-induced volatility but it is not robust to cross-correlation. Thus we use the simple adjustment proposed by Kolari and Pynnönen (2010) that takes into account the cross-correlation among the event on a same date. BMP t-statistic adjusted for cross-sectional correlation of abnormal returns can be computed as follows:

$$
t_{A B M P}=t_{B M P} \sqrt{\frac{1-\bar{\rho}}{1+(N-1) \bar{\rho}}}
$$

where $\bar{\rho}$ is the average of the sample cross-sectional correlations of the estimationperiod residuals.

Wilcoxon Signed Rank test is used as a non-parametric test in this study since it considers that both the sign and the magnitude of abnormal returns are significant. The test statistic is given by:

$$
W_{t}=\sum_{i=1}^{N} r_{i}^{+}
$$

where $r_{i}{ }^{+}$is the positive rank of the absolute value of abnormal returns. The test statistic for testing null hypothesis is then defined as:

$$
z_{\text {wilcoxon, } t}=\frac{W-N(N-1) / 4}{\sqrt{N(N+1)(2 N+1) / 12}}
$$


To determine for abnormal trading volume we use the Harris and Gurel (1986) methodology.

$$
V R_{i t}=\frac{V_{i t} / V_{m t}}{V_{i} / V_{m}}-1
$$

where $V_{i t}$ and $V_{m t}$ are the trading volumes of stock $i$ and of the market portfolio $m$ at time $t$, respectively. $V_{i}$ and $V_{m}$ are the average trading volumes of stock and market during the period from $\mathrm{AD}-125$ to $\mathrm{AD}-6$. The volume ratio, $V R_{i t}$ is a standardized measure of the trading volume of stock $i$ in the time period $t$, adjusted for the marketwide changes. Its expected value is 0 if there is no change in the volume during the event date relative to the estimation period. The $V R_{i t}$ is also tested by adjusted BMP t-statistic and Wilcoxon Signed Rank test.

\section{Empirical Results and Discussion}

We analyze the results of the study with respect to the price movements and trading volumes separately, in the following sections.

\subsection{Price Results}

Table 2 presents the Cumulative Abnormal Returns (CAR) for index addition (Panel A) and index deletion (Panel B), in the event windows for the Participation-30 Index. Panel A shows that the calculated CARs are predominantly negative for all sub event windows except the days $(\mathrm{ED}+1, \mathrm{ED}+3)$ and $(\mathrm{ED}+1, \mathrm{ED}+4)$. Days (AD-5,AD-1) and (AD-3,AD-1) decrease by $1.58 \%$ and $1.15 \%$ respectively with statistically significant difference at the 0.05 level for the non-parametric test. On the Effective Date (ED) and Announcement Date (AD) we observe negative abnormal returns of $-0.41 \%$ and $-0.39 \%$ respectively; but only (AD) is statistically significant according to the $Z_{\text {wilcoxon }}$ test at 0.10 level. In all but one $(\mathrm{ED}+1, \mathrm{ED}+4)$ of the examined days, the number of negative stocks are much more than the positive ones.

The results of index deletions (Panel B) are almost the exact opposite of index additions (Panel A). Positive CARs are calculated in the pre-announcement and post-effective periods. During the pre-announcement period all CARs are statistically significant at the conventional levels according to both of the parametric and non-parametric tests, except the day (AD-2,AD-1) in the parametric test. The CAR for the day (AD-3,AD-1) is $1.51 \%$, and statistically significant at the 0.05 and 0.01 levels in parametric and nonparametric tests, respectively. In addition, the day (AD-3,AD-1) has the maximum 
number of positive stocks (22-8). Likewise, the stocks that are deleted from the index generate negative CARs in the announcement $(-0.50 \%)$ and the effective $(-0.38 \%)$ dates. The announcement date result is statistically significant at 0.05 level in both tests.

Table 2: Daily Cumulative Abnormal Returns (CARs)

\begin{tabular}{|c|c|c|c|c|c|c|c|c|c|}
\hline \multicolumn{2}{|c|}{ Event Window } & \multicolumn{3}{c|}{ Panel A - Index Additions } & \multicolumn{3}{c|}{ Panel B - Index Deletions } \\
\hline \multicolumn{1}{|c}{ Period Name } & Period Time & $\mathbf{C A R}$ & $\mathbf{t}_{\text {abhm }}$ & $\mathbf{z}_{\text {wilcoxon }}$ & $>\mathbf{0}-<\mathbf{0}$ & $\mathbf{C A R}$ & $\mathbf{t}_{\text {abhm }}$ & $\mathbf{z}_{\text {wilcoxon }}$ & $>\mathbf{0}$-<0 \\
\hline Pre-Announcement & AD-5,AD-1 & $-1.58 \%$ & -1.007 & $-2.217^{* *}$ & $18-33$ & $1.65 \%$ & $2.156^{* *}$ & $-2.078^{* *}$ & $19-11$ \\
\hline & AD-4,AD-1 & $-1.16 \%$ & -0.820 & -1.476 & $20-31$ & $1.42 \%$ & $1.887^{*}$ & $-1.800^{*}$ & $18-12$ \\
\hline & AD-3,AD-1 & $-1.15 \%$ & -0.972 & $-2.062^{* *}$ & $22-29$ & $1.51 \%$ & $2.156^{* *}$ & $-2.602^{* * *}$ & $22-8$ \\
\hline & AD-2,AD-1 & $-0.70 \%$ & -0.598 & -1.176 & $25-26$ & $0.78 \%$ & 1.340 & $-1.719^{*}$ & $17-13$ \\
\hline \multirow{2}{*}{ Announcement } & AD-1 & $-0.25 \%$ & -0.426 & -1.425 & $20-31$ & $0.79 \%$ & $1.761^{*}$ & $-1.697^{*}$ & $15-15$ \\
\hline Post-Announcement & AD & $-0.39 \%$ & -0.709 & $-1.879^{*}$ & $21-30$ & $-0.50 \%$ & $-2.529^{* *}$ & $-2.180^{* *}$ & $12-18$ \\
\hline & AD+1 & $-0.18 \%$ & -0.205 & -1.176 & $22-29$ & $0.00 \%$ & -0.207 & -0.586 & $13-17$ \\
\hline Effective & ED & $-0.19 \%$ & -0.489 & -1.636 & $19-32$ & $-0.38 \%$ & $-1.730^{*}$ & -1.635 & $11-19$ \\
\hline Post-Effective & ED+1 & $-0.26 \%$ & -0.482 & -1.490 & $19-32$ & $0.40 \%$ & $1.787^{*}$ & -1.255 & $17-13$ \\
\hline & ED+1,ED+2 & $-0.24 \%$ & -0.499 & -1.052 & $19-32$ & $0.48 \%$ & 1.274 & -1.388 & $15-15$ \\
\hline & ED+1,ED+3 & $0.08 \%$ & -0.209 & -0.548 & $22-29$ & $0.36 \%$ & 0.657 & -0.668 & $16-14$ \\
\hline & ED+1,ED+4 & $0.16 \%$ & -0.201 & -0.127 & $26-25$ & $0.14 \%$ & -0.109 & -0.910 & $17-13$ \\
\hline & ED+1,ED+5 & $-1.00 \%$ & -0.863 & $-1.753^{*}$ & $22-29$ & $0.14 \%$ & 0.065 & -0.381 & $13-17$ \\
\hline
\end{tabular}

Note: This table presents the daily CARs of addition and deletion to Participation Index with five sub event-windows. Notice that the announcement date and effective date are denoted as AD and ED, respectively. Results are shown in two parts. Panel A (Columns 3-6) is related to the index addition and Panel B (Columns 7-10) is related to the index deletion. The $3^{\text {rd }}$ and $7^{\text {th }}$ columns show daily CARs results. The $4^{\text {th }}$ and $8^{\text {th }}$ columns demonstrate the parametric test results. Column 5 and 9 show the non-parametric test. Finally the $6^{\text {th }}$ and $10^{\text {th }}$ columns are the number of positive and negative abnormal returns for the analyzed stocks.

$* * *, * *$, and $*$ indicate significance at the 1,5 , and 10 percent levels respectively.

\subsection{Trading Volume}

The results for the impact of addition/deletion of stocks to the Participation-30 Index on trading volume are indicated in Table 3. Findings show that trading volumes are highly above the normal levels at days (AD-5,AD-1 and AD-4,AD-1) for the added 
and deleted stocks; but not statistically significant. During the post-announcement periods and the effective date, abnormal trading volumes are found to be negative when compared to the normal level, for the included stocks; and this is statistically significant according to the non-parametric test.

The abnormal volume of included stocks is $21.0 \%$ higher than the normal level on the announcement day, whereas it is $15.2 \%$ lower than the normal level in the effective date. Negative abnormal trading volume stocks seem to be markedly higher than the positive ones on the effective date and post-effective periods for index deletions.

Table 3: Daily Cumulative Abnormal Trading Volumes (CATVs)

\begin{tabular}{|l|c|c|c|c|c|c|c|c|c|}
\hline \multicolumn{2}{|c|}{ Event Window } & \multicolumn{3}{|c|}{ Index Additions } & \multicolumn{3}{c|}{ Index Deletions } \\
\hline Period Name & Period Time & CATV & $\mathbf{t}_{\text {abhm }}$ & $\mathbf{z}_{\text {wicoxon }}$ & $>\mathbf{0 - < 0}$ & $\mathbf{C A T V}$ & $\mathbf{t}_{\text {abhm }}$ & $\mathbf{z}_{\text {wilcoxon }}$ & $\begin{array}{c}>\mathbf{0 -} \\
<\mathbf{0}\end{array}$ \\
\hline Pre-Announcement & AD-5,AD-1 & 2.522 & 0.897 & -0.431 & $19-32$ & 2.092 & 1.534 & -0.874 & $17-13$ \\
\hline & AD-4,AD-1 & 1.654 & 0.935 & -0.778 & $20-31$ & 1.118 & 1.388 & -0.792 & $14-16$ \\
\hline & AD-3,AD-1 & 0.904 & 0.801 & -0.300 & $22-29$ & 0.957 & 1.439 & -0.895 & $13-17$ \\
\hline & AD-2,AD-1 & 0.618 & 0.804 & -0.319 & $24-27$ & 0.781 & 1.342 & -0.298 & $12-18$ \\
\hline & AD-1 & 0.321 & 0.907 & -0.797 & $26-25$ & 0.543 & 1.159 & -0.545 & $10-20$ \\
\hline Announcement & AD & 0.210 & 0.590 & -0.553 & $21-30$ & 0.788 & 1.618 & -0.175 & $13-17$ \\
\hline Post-Announcement & AD+1 & -0.127 & -0.481 & $-2.793^{* * *}$ & $19-32$ & -0.049 & -0.454 & -0.833 & $14-16$ \\
\hline & AD+1,AD+2 & -0.204 & -0.344 & $-2.493^{* *}$ & $20-31$ & 0.324 & 0.885 & -0.134 & $15-15$ \\
\hline Effective & ED & -0.152 & -0.643 & $-3.187^{* * *}$ & $17-34$ & -0.091 & -0.748 & $-1.676^{*}$ & $7-23$ \\
\hline Post-Effective & ED+1 & 0.001 & 0.001 & $-1.903^{*}$ & $18-33$ & 0.083 & 0.322 & -1.409 & $8-22$ \\
\hline & ED+1,ED+2 & -0.009 & -0.019 & -1.125 & $21-30$ & 0.097 & 0.256 & -1.635 & $10-20$ \\
\hline & ED+1,ED+3 & 0.007 & 0.011 & -0.876 & $22-29$ & -0.115 & -0.273 & $-1.697^{*}$ & $8-22$ \\
\hline & ED+1,ED+4 & 0.162 & 0.193 & 0.591 & $24-27$ & -0.282 & -0.587 & -1.635 & $8-22$ \\
\hline & ED+1,ED+5 & 0.197 & 0.191 & -0.544 & $25-26$ & -0.170 & -0.298 & -1.203 & $10-20$ \\
\hline
\end{tabular}

Note: This table presents the daily CATVs of addition and deletion to Participation Index with five sub event- windows. CATV is the cumulative cross sectional average of stocks'trading volumes adjusted for total market volume.

$* * * * *$, and $*$ indicate significance at the 1,5 , and 10 percent levels respectively.

\subsection{Discussion}

One would expect that additions affect positively while deletions affect negatively. Nevertheless, based on the above results, our findings are not much consistent with the expectations. Negative returns are observed during almost all the analyzed periods for 
index addition; while positive returns are found for index deletions, except two days. For our sample of 51 addition, we find that the number of positive stocks are more than the negative stocks, except one day; whereas reverse situation is observed for the sample of 30 deletions.

Trading volume increases during the pre-announcement and announcement periods but this change is not found to be statistically significant. Contrarily, it decreases during the post-announcement and effective periods for index additions by showing a statistical significance only in non-parametric test. Our sample of 30 deletions has higher volumes during the pre-announcement and announcement periods as in index addition; in the remaining periods trading volume follows a mixed trend.

We think three factors to be effective on that the results are not consistent with our expectations. The first one is the lack of recognizability and products about Participation Index. In recent years, the development in non-banking areas of Islamic Finance has accelerated in Turkey; offering a new alternative to the investors who have religious and ethical sensitivity. None the less, the product range in the Participation Index is very limited, especially for mutual funds. It can be due to the short history of the index.

We think that the second effect can be the attitude of the domestic investors who have religious sensitivity. It is a common belief in Turkey that something is forbidden regardless of its amount. For instance, even a little amount of alcohol is considered as prohibited; although it does not make someone drunk. In a similar manner, most of the domestic investors who are aware of the Participation Index are not satisfied with the financial ratio filtering. Because of this thought, they avoid from Participation Index.

Finally, a company can take place in a Participation Index by chance or not necessarily by choice. It is included in the Participation Index when the financial ratios are suitable or vice versa. In Malaysia, Abdullah and Bacha (2001) claim that it may be worthwhile for a company to get its stocks on the SAC list and ensure it remains there, from a stock issuing company viewpoint. However, there are no similar thoughts and feelings in many Turkish companies on Borsa Istanbul, to the best of our knowledge.

\section{Conclusions}

In this paper, we examine the effects of addition and deletions to the Participation-30 Index on the performance of stocks during the period April 2011 - June 2015. The performance is measured in terms of stock returns and trading volumes. Our results show that stock prices respond negatively to the index additions and positively to the 
index deletions in general, for the research periods. On the announcement and effective days, negative returns are found both for index additions and deletions. Results are varied for the trading volumes. Trading activity of added and deleted stocks is affected positively in the announcement day; while the effective day exhibits an exact opposite behaviour.

When compared to the previous research, our findings appear in line with Sadeghi's (2015) study. His results show that the prices of eligible stocks respond positively to the index additions for Muslim countries and negatively for non-Muslim countries. Our results are similar to the non-Muslim countries. Although the vast majority of the population in Turkey is Muslim, the reasons behind these results can be the following: lack of recognizability and products about Participation Index, opinions of the domestic investors with religious sensitivity related to the index. Furthermore, most of the listing companies' perspectives are similar to the counterparts in Western Countries.

The following suggestions can be done related to the Participation Index. Firstly, generating new indices and diversification of the new products on the indices will draw the interest of foreign investors, especially Arabs. Secondly, there is a strong need for improving the awareness and information of faithful individual investors by the scholars who have both solid religious and financial knowledge. Well-respected scholars' and financial experts' comments will clarify confused minds. Lastly, studies should be done to change the perspectives of the listed companies and reveal the privileges of the Participation Index. We believe that these suggestions will further improve the importance and impact of the Participation Index.

\section{References}

Abdullah, M., \& Bacha, O. (2001). Halal Stock Designation and Impact on Price and Trading Volume. The Journal of Accounting, Commerce \& Finance-Islamic Perspective, 66-97.

Ameer, R. (2015). Idiosyncratic Risk of Investing in Islamic Capital Market Equities. The Journal of Investing, 24(2), 79-89. Retrieved from http://papers.ssrn.com/sol3/papers. cfm?abstract_id $=2189935$

Arouri, M. E., Ben Ameur, H., Jawadi, N., Jawadi, F., \& Louhichi, W. (2013). Are Islamic finance innovations enough for investors to escape from a financial downturn? Further evidence from portfolio simulations. Applied Economics, 45(24), 3412-3420. http://doi.org/10.1080/00 036846.2012.707776

Basdas, U., \& Oran, A. (2014). Event studies in Turkey. Borsa Istanbul Review, 14(3), 167188. http://doi.org/10.1016/j.bir.2014.03.003 
Boehmer, E., Musumeci, J., \& Poulsen, A. B. (1991). Event-study methodology under conditions of event-induced variance. Journal of Financial Economics, 30(2), 253-272. http:// doi.org/10.1016/0304-405X(91)90032-F

Chakrabarti, R., Huang, W., Jayaraman, N., \& Lee, J. (2005). Price and volume effects of changes in MSCI indices - nature and causes. Journal of Banking \& Finance, 29(5), 12371264. http://doi.org/10.1016/j.jbankfin.2004.04.002

Cheung, A., Wai K., \& Roca, E. (2013). The effect on price, liquidity and risk when stocks are added to and deleted from a sustainability index: Evidence from the Asia Pacific context. Journal of Asian Economics, 24, 51-65. http://doi.org/10.1016/j.asieco.2012.08.002

Consolandi, C., Jaiswal-Dale, A., Poggiani, E., \& Vercelli, A. (2009). Global Standards and Ethical Stock Indexes: The Case of the Dow Jones Sustainability Stoxx Index. Journal of Business Ethics, 87(S1), 185-197. http://doi.org/10.1007/s10551-008-9793-1

El Khamlichi, A., Sannajust, A., \& Sarkar, H. K. (2014). Islamic Equity Indices: Insight and Comparison with Conventional Counterparts. Bankers, Markets \& Investors, (130), 69-80.

Eventstudytools. Retrieved December 31, 2015, from http://www.eventstudytools.com/ discussion-and-limitations.

Febrian, E., Erwany, A., \& Primadhi, A. (2013). Change of Islamic Index : Evidence From. The International Journal of Business and Finance Research, 7(5), 23-35.

Ghoul, W., \& Karam, P. (2007). MRI and SRI Mutual Funds: A Comparison of Christian, Islamic (Morally Responsible Investing) and Social Responsible Investing (SRI) Mutual Funds. The Journal of Investing. http://doi.org/10.3905/joi.2007.686416

Harris, L., \& Gurel, E. (1986). Price and Volume Effects Associated with Changes in the S\&P 500 List: New Evidence for the Existence of Price Pressures. The Journal of Finance, 41(4), 815-829. http://doi.org/10.1111/j.1540-6261.1986.tb04550.x

Hassan, M. K., \& Girard, E. (2011). Faith-Based Ethical Investing: The Case of Dow Jones Islamic Indexes. Networks Financial Institute Working Paper, 2011-WP:06, 1-41.

Ho, C. S. F., Abd Rahman, N. A., Yusuf, N. H. M., \& Zamzamin, Z. (2014). Performance of global Islamic versus conventional stock indices: International evidence. Pacific-Basin Finance Journal, 28, 110-121. http://doi.org/10.1016/j.pacfin.2013.09.002

Kolari, J. W., \& Pynnönen, S. (2010). Event Study Testing with Cross-sectional of Abnormal Returns. Review of Financial Studies, 23(11), 3996-4025.

Lynch, A. W., \& Mendenhall, R. R. (1996). New Evidence on Stock Price Effects Associated with Charges in the S\&P 500 Index. Retrieved from http://papers.ssrn.com/abstract=1298790

MacKinlay, A. C. (1997). Event Studies in Economics and Finance. Journal of Economic Literature, XXXV(March), 13-39. http://doi.org/10.2307/2729691

Participation 30 Index Rules Booklet. Retrieved December 28, 2015, from www.katilimendeksi.org Sadeghi, M. (2008). Financial Performance of Shariah-Compliant Investment : Evidence from Malaysian Stock Market. International Research Journal of Finance and Economics, (20), 15-26. 
Sadeghi, M. (2011). Shariah- compliant Investment and Stockholders' Value : An Empirical Investigation Sadeghi, 4(1), 44-61.

Sadeghi, M. (2014). Are Faithful Investors Rewarded by the Market Place ? Evidence from Australian Shariah-compliant Equities Sadeghi. International Review of Business Research Papers, 10(2), 160-177.

Sadeghi, M. (2015). Is Shariah-compliant investment universally sustainable? A comparative study. Islamic Banking and finance-Essays on Corporate Finance, Efficiency and Product Development, 81-91.

Savaşan, F., Yardımoğlu, F., \& Beşel, F. (2015). The Effect of Exogenous Shocks on Participation Index of Borsa Istanbul : Permanent or Temporary? International Journal of Islamic Economics and Finance Studies, 1(1), 81-92.

State of the Global Islamic Economy Report 2015-2016 Report. (2015).

Yanpar, A. (2014). Íslami Finans Illkeler, Araçlar ve Kurumlar. First ed., Scala Publishing, İstanbul.

Yazi, E., Morni, F., \& Saw, I. S. (2015). The Effects of Shariah Compliance Announcement towards Stock Price Changes in Malaysia. Journal of Economics, Business and Management, 3(11), 1019-1023. http://doi.org/10.7763/JOEBM.2015.V3.327

Yıldız, S. B. (2015). Katılım 30 Endeksi İle BİST 100 Endeksi 'nin Performanslarının Değerlendirilmesi. Finans Politik \& Ekonomik Yorumlar, 52(606), 41-54. 